\title{
Theoretical Studies of Hydrogen Bond Interactions in Fluoroacetic Acid Dimer
}

\author{
Alireza Najafi Chermahini, ${ }^{*}$ Mohsen Mahdavian, and Abbas Teimouri ${ }^{\dagger}$
Department of Chemistry, Faculty of Science, Yasouj University, Yasouj, 75918-74831, Iran. "E-mail: najafi@mail.yu.ac.ir ${ }^{\dagger}$ Payame Noor University (PNU), Isfahan, P. O. Box 81395-671, Iran
Received July 25, 2009, Accepted February 17, 2010

\begin{abstract}
$\mathrm{Ab}$ initio and density functional theory methods have been employed to study all theoretically possible conformers of fluoroacetic acid. Molecular geometries and energetic of cis and trans monomers and cis dimers in gaseous phase have been obtained using HF, B3LYP and MP2 levels of theory, implementing 6-311++G(d,p) basis set. It was found that cis rotamers are more stable. In addition, it was found that in comparison with acetic acid the strength of hydrogen bonding in fluoroacetic acid decreased. The infrared spectrum frequencies and the vibrational frequency shifts are reported. Natural population and atom in molecule analysis performed to predict electrostatic interactions in the cyclic $\mathrm{H}$-bonded complexes and charges. The proton transfer reaction is studied and activation energy is compared with acetic acid proton transfer reaction.
\end{abstract}

Key Words: Hydrogen bonding, Fluoroacetic acid, Conformational analysis, NBO analysis

\section{Introduction}

Hydrogen bonding has been a very interesting issue for chemists for a long time since it can account for characteristics of many chemical and biological phenomena. A sound knowledge of hydrogen bond is fundamental to understand chemical structures, enzyme catalysis, material properties, self assembly phenomena, and functions of molecular and biological devices and machines. ${ }^{1-3}$ It is well known that carboxylic acids form in the gas phase and solution cyclic structure with two very strong $\mathrm{O}-\mathrm{H} \cdots \mathrm{O}=\mathrm{C}$ hydrogen bonds. Several experimental studies such as IR spectroscopy, ${ }^{4,5}$ NMR spectroscopy, ${ }^{6-8}$ X-ray crystallography, ${ }^{9-11}$ microwave spectroscopy ${ }^{12}$ vapor-density measurements ${ }^{13}$ and thermal conductivity measurements ${ }^{14}$ indicate that

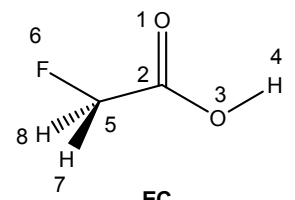

EC

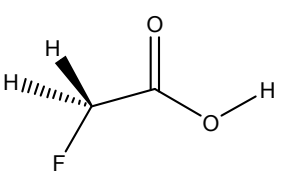

BC

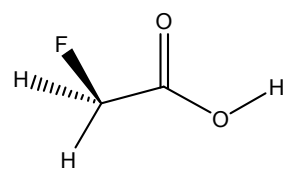

SC1

Cis Conformer<smiles>O=C(O)C(F)F</smiles>

SC

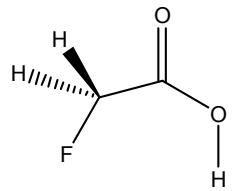

BT

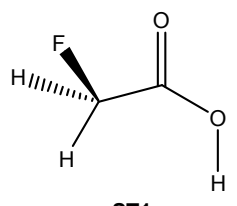

Trans Conformer

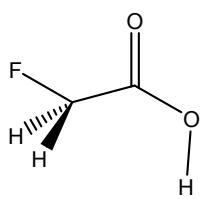

ET

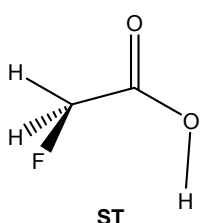

ST carboxylic acids form hydrogen-bonded cyclic dimers. In addition the characterization of the hydrogen bonding interaction between carboxylic acids has been studied by a lot of theoretical calculations. ${ }^{15-20}$

The monomers of carboxylic acids may be found in two forms: cis and trans (Figure 1). In the cis conformer the carboxylic hydrogen atom points toward the carbonyl group, while in the trans conformer the two point away from each other. Generally monocarboxylic acids exhibit only the cis conformer. The coexistence of both conformers of formic acid in the solid state was proposed earlier, ${ }^{21}$ but this possibility was excluded by a reinvestigation of the crystal structure. ${ }^{22}$ Nevertheless, a recent study has shown that both conformers indeed coexist at high pressure. ${ }^{23}$ In addition, the trans and cis conformers have been observed in water ${ }^{24,25}$ and in the gas phase. ${ }^{26}$

Fluoroacetic acid is the simplest molecule in the series of $\alpha$-substituted halogenated carboxylic acids. According to previous experimental data Van Eijck et al. have studied the rotamers of fluoroacetic acid by electron diffraction and microwave techniques. ${ }^{12}$ They proved the existence of two conformers in the gas phase, labeled EC and BT in this paper. However, Nieminen et al. theoretically showed that fluoroacetic acid exists in four conformers. ${ }^{27}$ The aim of the present paper is a careful study of fluoroacetic acid in all their possible conformations, performed by DFT and ab initio methods, in order to obtain further and more detailed information on geometrical parameters of molecule and on the rotational motion of the $\mathrm{CH}_{2} \mathrm{~F}$ group. Besides, the present calculations may serve to estimate the strength of hydrogen bonding in the fluoroacetic acid dimers. It is important that we compare the effect of replacing of a hydrogen atom with an electron withdrawing atom ( $\mathrm{F}$ atom) on hydrogen bonding of acetic acid.

\section{Computational Methods}

The ground-state properties of the monomers and the dimers of fluoroacetic acid have been calculated by using HF, B3LYP

conformers of fluoroacetic acid. 
and MP2 methods at 6-311++G(d,p) basis set level. All computations have been performed on a personal computer using the Gaussian 03 program package ${ }^{28}$ and Gaussview molecular visualization program. ${ }^{29}$ The scale factor 0.9614 for calculated frequencies was used for B3LYP with $6-311++\mathrm{G}(\mathrm{d}, \mathrm{p})$ basis set. ${ }^{30}$ All the equilibrium isomers without imaginary frequency correspond to the local minimum points on the potential surface. A single imaginary frequency was confirmed for the transition states. The uncorrected interaction energies were obtained by subtracting the energy of two fully optimized monomers from the energy of the dimers:

$$
\mathrm{E}_{\text {int }}=\mathrm{E}_{\mathrm{A}-\mathrm{B}}-\left(\mathrm{E}_{\mathrm{A}}+\mathrm{E}_{\mathrm{B}}\right)
$$

where $\mathrm{E}_{\mathrm{A}}, \mathrm{E}_{\mathrm{B}}$ and $\mathrm{E}_{\mathrm{A}-\mathrm{B}}$ are the electronic energies of first fluoroacetic acid molecule, second one and dimer, respectively. The zero-point vibrational energy (ZPVE) corrections are applied in the present work based on following equations:

$$
\mathrm{E}_{\text {int(ZPVE })}=\mathrm{E}_{\mathrm{A}-\mathrm{B}(\mathrm{ZPVE})}-\mathrm{E}_{\mathrm{A}(\mathrm{ZPVE})}-\mathrm{E}_{\mathrm{B}(\mathrm{ZPVE})}
$$

where $\mathrm{E}_{\mathrm{A}(\mathrm{ZPVE})}, \mathrm{E}_{\mathrm{B}(\mathrm{ZPVE})}$ and $\mathrm{E}_{\mathrm{A}-\mathrm{B}(\mathrm{ZPVE})}$ are the sum of electronic and zero-point energies of first and second fluoroacetic acid and aggregated system, respectively. To correct the basis set superposition error (BSSE), the counterpoise (CP) method ${ }^{31}$ was employed.

Finally, the corrected interaction energies $\mathrm{E}_{\text {int(corr), was cal- }}$ culated by addition of $E_{\text {int(ZPVE) }}$ and $E_{\text {int(BSSE) }}$ to interaction energy term (eq. 1):

$$
\mathrm{E}_{\text {int(corr) }}=\mathrm{E}_{\text {int }}+\mathrm{E}_{\text {int(ZPVE })}+\mathrm{E}_{\text {int(BSSE) }}
$$

The vibrational frequencies were computed for the optimized geometries of monomers and dimers of $\mathrm{FCH}_{2} \mathrm{CO}_{2} \mathrm{H}$. The harmonic frequency shift of the $\mathrm{O}-\mathrm{H}$ stretching mode in the dimers, $v_{\mathrm{O}-\mathrm{H}}$, was estimated by the following equation:

$$
\Delta v_{\mathrm{O}-\mathrm{H}}=v_{\mathrm{O}-\mathrm{H}(\text { Dimer })}-v_{\mathrm{O}-\mathrm{H}(\text { Monomer })}
$$

The natural bond orbital (NBO) analysis was used to understand better the nature of the corresponding intermolecular interactions. $^{32}$

\section{Results and Discussion}

The structures and numbering of eight conformers of fluoroacetic acid to be theoretically possible are presented in Figure 1. For the titled molecule two conformations for the $\mathrm{OH}$ group and three conformers for fluoro group have been considered, the adopted nomenclatures are EC and ET for eclipsed fluoro and cis or trans of hydrogen with carbonyl group. SC and ST refer to staggered fluoro for cis and trans locations of hydrogen and carbonyl group, SC1 and ST1 to other staggered fluoro for cis and trans locations of hydrogen and carbonyl group, and BC and BT to cis and trans bisected conformers, respectively. Among the calculated isomers we only consider four conformers: ET, EC, ST, SC.

Monomers. The properties of isolated conformers of fluoroacetic acid, well reproduced at the HF, DFT and MP2 using $6-311++G(d, p)$ basis set are presented in Table 1. The results are compared with the values reported from experimental studies. A close look at the calculated and the experimental structural parameters shows that for EC and BT conformers for which experimental data are available, HF bond distances are slightly shorter than the experimental results. This may be due to neglect of the electron correlation by HF theory. However bond lengths and bond angles obtained by MP2 and DFT calculations are close to the experimental values, (See Table 1).

For example, comparison of C-O bond length calculated by DFT method with experimental data for EC and $\mathbf{B C}$ isomers shows differences of $0.37 \%$ and $0.41 \%$, exhibiting excellent agreement. When considering the good reliability of the calculated structures of species EC and BT, it seems to be reasonable to assume that calculated values for ET and B are also reliable.

The effect of replace of a hydrogen atom with a fluorine atom on the geometrical parameters can be compared with the acetic

Table 1. Some optimized geometric parameters of the four lowest energy conformers of fluoroacetic acid obtained at different levels of theory with the $6-311++G(d, p)$ basis set

\begin{tabular}{clccccccccc}
\hline & Method & $\mathrm{r}_{12}{ }^{a}$ & $\mathrm{r}_{23}$ & $\mathrm{r}_{34}$ & $\mathrm{r}_{25}$ & $\mathrm{r}_{56}$ & $\Theta_{234}{ }^{b}$ & $\Theta_{521}$ & $\Phi_{1256}{ }^{b}$ & $\Phi_{1234}$ \\
\hline EC & HF & 1.175 & 1.328 & 0.946 & 1.510 & 1.347 & 109.4 & 126.2 & 0.0 & 0.0 \\
& B3LYP & 1.197 & 1.355 & 0.969 & 1.518 & 1.377 & 107.7 & 126.4 & 0.0 & 0.0 \\
& MP2 & 1.204 & 1.356 & 0.968 & 1.517 & 1.373 & 106.4 & 126.5 & 0.0 & 0.0 \\
ET & HF & 1.169 & 1.334 & 0.943 & 1.517 & 1.343 & 113.4 & 124.5 & 0.0 & 180.0 \\
& B3LYP & 1.191 & 1.362 & 0.966 & 1.527 & 1.374 & 112.0 & 124.9 & 0.0 & 180.0 \\
& MP2 & 1.197 & 1.363 & 0.964 & 1.526 & 1.369 & 110.3 & 125.0 & 0.0 & 180.0 \\
BC & HF & 1.182 & 1.314 & 0.947 & 1.512 & 1.352 & 108.9 & 121.2 & 180.0 & 0.0 \\
& B3LYP & 1.205 & 1.341 & 0.970 & 1.517 & 1.382 & 107.3 & 121.6 & 180.0 & 0.0 \\
& MP2 & 1.210 & 1.342 & 0.969 & 1.516 & 1.376 & 105.8 & 121.6 & 180.0 & 0.0 \\
BT & HF & 1.176 & 1.317 & 0.945 & 1.512 & 1.368 & 111.6 & 120.4 & 180.0 & 180.0 \\
& B3LYP & 1.198 & 1.342 & 0.970 & 1.524 & 1.404 & 109.5 & 121.0 & 180.0 & 180.0 \\
& MP2 & 1.204 & 1.344 & 0.968 & 1.524 & 1.394 & 108.0 & 120.9 & 180.0 & 180.0 \\
EC & Exp $^{c}$ & 1.201 & 1.360 & 0.983 & 1.497 & 1.365 & 105.6 & 126.9 & - & - \\
BT & Exp $^{d}$ & 1.207 & 1.337 & 0.938 & 1.510 & 1.390 & 108.4 & 120.8 & - & - \\
\hline
\end{tabular}

${ }^{a}$ Bond lengths in $\AA,{ }^{b}$ Bond angles and dihedral angles in degree ${ }^{c, d}$ Experimental data from [12 a] and [12 b]. 

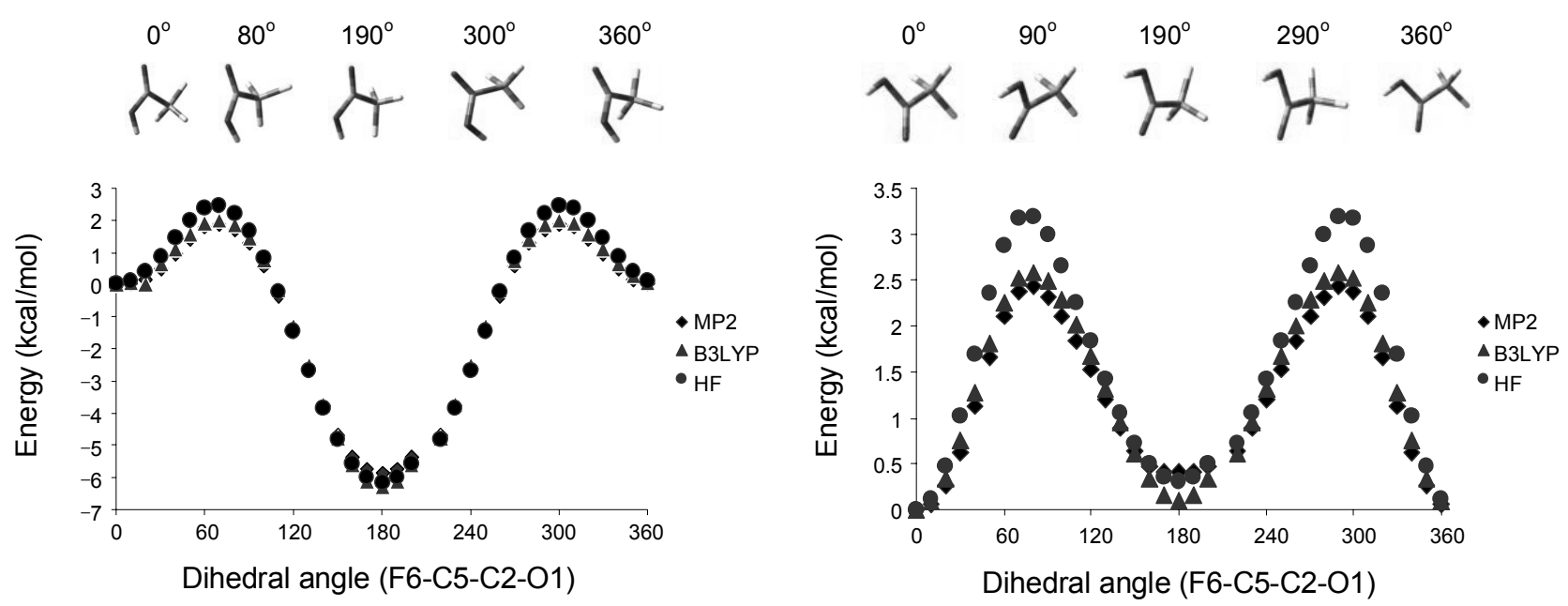

Figure 2. Rotational potential energy of cis and trans fluoroacetic acid as a function of F6-C5-C2-O1 using different levels of theory.

acid geometries. For example in the acetic acid, the previously calculated $\mathrm{C}=\mathrm{O}$ and $\mathrm{C}-\mathrm{C}$ bond lengths using MP2/6-31G* method were reported as $1.2170 \AA$ and $1.5001 \AA$ respectively. ${ }^{33}$ Comparison with our results shows that fluorination causes a decrease in the $\mathrm{C}=\mathrm{O}$ and $\mathrm{C}-\mathrm{O}$ bond lengths and increase in the $\mathrm{C}-\mathrm{C}$ bond length. For instance, the $\mathrm{C}=\mathrm{O}$ bond length calculated at MP2/6-311++G(d,p) level decreased to $1.2037,1.1976$, $1.2100 \AA$ and 1.2038 for the EC, ET, BC and BT isomers, respectively.

Conformational analysis of the two conformers (cis and trans fluoroacetic acid) was carried out initially to find some of the structures corresponding to the conformers with lowest energy. For this purpose, F6-C5-C2-O1 dihedral angle was considered on each molecule, to investigate the overall influence on the total energy of the molecule. Figure 2 shows that cis or trans fluoroacetic acid have two stable conformers: EC, BC ET and BT for cis and trans isomers, respectively. In the cis and trans isomers, the lowest energy conformers reside where the dihedral angle takes the values $0^{\circ}$ and $190^{\circ}$, respectively. The intramolecular hydrogen bonding causes the BT rotamer to be more stable than ET one. However the maxima were obtained when F6-C5C2-O1 dihedral angle takes $80^{\circ}, 300^{\circ}$ for cis and $90^{\circ}$ and $290^{\circ}$ for trans isomers, respectively (Figure 2).
The results of calculated total energies, relative stabilities and dipole moments of four conformers of $\mathrm{FCH}_{2} \mathrm{CO}_{2} \mathrm{H}$ are collected in Table 2. As can be seen in Table 2, all methods predict that the most stable conformer is obtained when fluorine atom is eclipsed with carbonyl group in the cis conformer. This observation is in consistence with previous finding about acetic acid that reported cis conformer is $6.1 \mathrm{kcal} / \mathrm{mol}$ more stable than trans, using MP2/6-311++G(d,p) level of theory. ${ }^{20}$ In addition, based on our calculations, the order of stability was found as $\mathbf{E C}>\mathbf{B C}>\mathbf{B T}>\mathbf{E T}$. The energetic order of four conformers of fluoroacetic acid was consistent at all levels of theory used (see Table 2). As the relative energies of the conformers are considered, it can be seen the relative instability ET and $\mathbf{B T}$ are higher than $\mathrm{kT}(0.6 \mathrm{kcal} / \mathrm{mol}$ at room temperature and $1 \mathrm{~atm}$. pressure); this means that both the trans conformers do not have considerable populations in the gas phase.

The HF theory predicts that $\mathbf{E C}$ is more stable than $\mathbf{B C}, \mathbf{B T}$ and $\mathbf{E T}$ by $0.32,2.05$ and $8.22 \mathrm{kcal} / \mathrm{mol}$, respectively. In addition these values for DFT methods are $0.12,0.65$ and $6.94 \mathrm{kcal} / \mathrm{mol}$ for BC, BT and ET, respectively. Moreover, the MP2 values are $0.41,1.29$ and $7.17 \mathrm{kcal} / \mathrm{mol}$ for BC, BT and ET, respectively.

Dipole moment is the first derivative of the energy with res-

Table 2. Calculated total energies, relative stabilities and dipole moments of fluoroacetic acid monomers at HF, B3LYP and MP2 levels using 6-311++G(d,p) basis set

\begin{tabular}{|c|c|c|c|c|}
\hline & EC & ET & BC & BT \\
\hline \multirow{3}{*}{$\mathrm{HF}$} & $-326.7545807^{a}$ & -326.7414869 & -326.7540736 & -326.7513054 \\
\hline & $0.0^{b}$ & 8.22 & 0.32 & 2.05 \\
\hline & $3.37^{c}$ & 5.38 & 0.1282 & 3.1594 \\
\hline \multirow{3}{*}{ B3LYP } & -328.4202460 & -328.4091942 & -328.4200627 & -328.4192143 \\
\hline & 0.0 & 6.94 & 0.12 & 0.65 \\
\hline & 3.1378 & 5.00 & 0.2805 & 2.8935 \\
\hline \multirow{3}{*}{ MP2 } & -327.6340906 & -327.6226611 & -327.6334373 & -327.6320269 \\
\hline & 0.0 & 7.17 & 0.41 & 1.29 \\
\hline & 3.44 & 5.52 & 0.20 & 3.28 \\
\hline
\end{tabular}

${ }^{a}$ Total energies in Hartree, ${ }^{b}$ Relative stabilities in Kcal $/ \mathrm{mol},{ }^{c}$ Dipole moments in Debye. 
Table 3. Some optimized geometrical parameters of the two dimers of fluoroacetic acid obtained at different levels of theory using the 6-311++G(d,p) basis set

\begin{tabular}{|c|c|c|c|c|c|c|}
\hline \multirow{2}{*}{ parameter } & \multicolumn{2}{|c|}{$\mathrm{HF}$} & \multicolumn{2}{|c|}{ B3LYP } & \multicolumn{2}{|c|}{ MP2 } \\
\hline & BC & EC & BC & EC & BC & EC \\
\hline $\mathrm{r}_{12}{ }^{a}$ & 1.197 & 1.189 & 1.225 & 1.217 & 1.228 & 1.220 \\
\hline $\mathrm{r}_{23}$ & 1.292 & 1.305 & 1.307 & 1.319 & 1.312 & 1.324 \\
\hline $\mathrm{r}_{25}$ & 1.510 & 1.509 & 1.516 & 1.517 & 1.515 & 1.516 \\
\hline$r_{34}$ & 0.960 & 0.960 & 1.000 & 0.998 & 0.993 & 0.991 \\
\hline$r_{57}$ & 1.082 & 1.083 & 1.093 & 1.094 & 1.093 & 1.093 \\
\hline$r_{14^{\prime}}$ & 1.832 & 1.844 & 1.674 & 1.681 & 1.689 & 1.698 \\
\hline $\mathrm{r}_{26}$ & 1.350 & 1.347 & 1.380 & 1.377 & 1.375 & 1.372 \\
\hline$r_{1^{\prime} 4}$ & 1.835 & 1.844 & 1.673 & 1.680 & 1.689 & 1.698 \\
\hline$\Theta_{234}^{b}$ & 110.7 & 111.2 & 110.2 & 110.6 & 108.4 & 108.9 \\
\hline$\Theta_{325}$ & 119.7 & 124.3 & 118.8 & 123.5 & 119.0 & 123.7 \\
\hline$\Theta_{341^{\prime}}$ & 172.3 & 171.4 & 177.1 & 176.7 & 178.5 & 178.3 \\
\hline$\Phi_{1234}{ }^{c}$ & 0.0 & 0.0 & 0.0 & 0.0 & 0.0 & 0.0 \\
\hline$\Phi_{213^{\prime} 4^{\prime}}$ & 1.0 & 0.3 & 1.3 & 0.5 & 0.0 & 30.3 \\
\hline
\end{tabular}

${ }^{a}$ Bond lengths in $\AA{ }^{b, c}$ Bond angles and dihedral angles in degree.

Table 4. Calculated binding energies ( $\mathrm{kcal} \mathrm{mol}^{-1}$ ) of the doubly hydrogen bonded $\mathbf{B C}$ and $\mathbf{E C}$ fluoroacetic acid dimers using the 6-311++G $(\mathrm{d}, \mathrm{p})$ basis set at HF, B3LYP and MP2 methods ${ }^{a}$

\begin{tabular}{llcccc}
\hline & & $\mathrm{E}_{\text {int }}$ & $\mathrm{E}_{\text {int(ZPVE) }}$ & $\mathrm{E}_{\text {int(BSSE) }}$ & $\mathrm{E}_{\text {int(Corr) }}$ \\
\hline EC & HF & 13.92 & 1.49 & 0.88 & 11.55 \\
& B3LYP & 16.15 & 1.31 & 0.84 & 14.00 \\
& MP2 & 15.83 & 1.45 & 2.75 & 11.63 \\
BC & HF & 13.46 & 1.46 & 0.94 & 11.06 \\
& B3LYP & 15.76 & 1.10 & 0.85 & 13.81 \\
& MP2 & 15.67 & 1.63 & 2.83 & 11.21 \\
\hline
\end{tabular}

${ }^{a}$ The values are in $\mathrm{kcal} \mathrm{mol}^{-1}$. Basis set superposition errors for hydrogen bound associates (BSSE) are estimated by the counterpoise method.

pect to an applied electric field and is the measure of the asymmetry in the molecular charge distribution. The results of calculated dipole moments of $\mathrm{FCH}_{2} \mathrm{CO}_{2} \mathrm{H}$ isomers are collected in the Table 2. ET conformer has the largest dipole moments, $5.38,5.00$ and 5.52 Debye at HF, DFT and MP2 level of theory.

Dimers. The strength of a localized H-bond (X-H Y) may be found from the shortening of $\mathrm{d}_{\mathrm{H}-\mathrm{Y}}(\mathrm{X}=\mathrm{O}, \mathrm{N}$ or $\mathrm{F})$, the elongation of $d_{X-H}$ and the red shifts of $v_{\mathrm{XH}}$. All of these indirect parameters are easily calculated from the optimized results for dimers and related monomers. In the present study only the cyclic dimers having two $\mathrm{O}-\mathrm{H} \cdots \mathrm{O}=\mathrm{C}$ hydrogen bonds were considered, as they were recognized as the most stable in experimental and theoretical studies, and the only one whose geometrical parameters were measured in the carboxylic acids. ${ }^{32}$ Figures 3 and 4 show cyclic conformation and numbering of $\mathbf{E C}$ and $\mathbf{B C}$ dimers and the optimized structures of these dimers calculated at B3LYP/6-311++G(d,p) level of theory, respectively.

A close look at the Table 3 indicates that complex formation induces a small elongation of the $\mathrm{O}-\mathrm{H}$ and $\mathrm{C}=\mathrm{O}$ bond lengths and decrease of C-O bond length. For the EC dimer, DFT (B3LYP) calculations suggest that the $\mathrm{O}-\mathrm{H}$ and $\mathrm{C}=\mathrm{O}$ bond lengths increase by 0.029 and $0.020 \AA$, respectively, while the $\mathrm{C}-\mathrm{O}$ bond
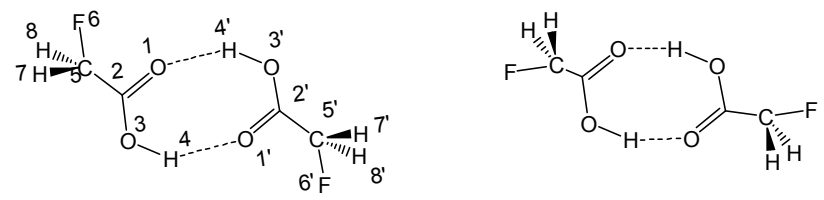

Figure 3. The schematic view and numbering of EC dimer (left) and BC dimer (right) of fluoroacetic acid.

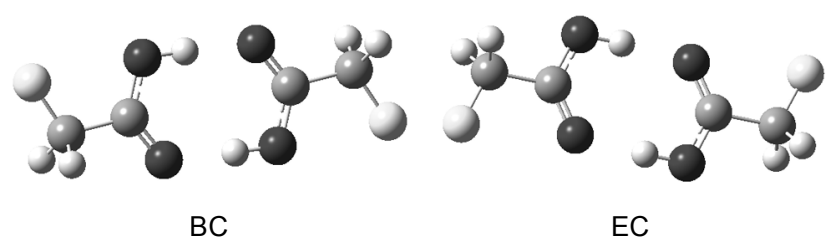

Figure 4. The optimized conformations of fluoroacetic acid dimers at B3LYP/6-311++G(d,p) level of theory.

shortens by $0.036 \AA$. The HF calculations predict an increase of 0.013 and $0.014 \AA$ in the bond lengths of $\mathrm{O}-\mathrm{H}$ and $\mathrm{C}=\mathrm{O}$, respectively, and a decrease of $0.023 \AA$ in the $\mathrm{C}-\mathrm{O}$ bond length. In addition, MP2 calculations show that the $\mathrm{O}-\mathrm{H}$ and $\mathrm{C}=\mathrm{O}$ bonds increase by 0.023 and $0.016 \AA$, respectively, while the $\mathrm{C}-\mathrm{O}$ bond shortens by $0.032 \AA$. A quite analogous effect was found for BC dimer. (See and compare Tables 1 and 4). The effect of fluorine atom on geometrical parameters in fluoroacetic acid dimer can be compared with acetic acid dimer. The aggregation in acetic acid causes $\mathrm{O}-\mathrm{H}$ and $\mathrm{C}=\mathrm{O}$ bonds increase by 0.019 and $0.015 \AA$ respectively, while the C-O bond decrease by $0.031 \AA$ calculated at MP2/6-31G(d) level of theory. ${ }^{20}$

Moreover, comparison of C2-O3-H4 bond angle between EC monomer and dimer show an increase by 1.8, 2.9 and 2.5 degree at the HF, DFT and MP2 methods, respectively. A similar change was found between $\mathbf{B C}$ monomer and dimer.

The results of calculated interaction energies for the $\mathbf{B C}$ and $\mathbf{E C}$ dimers are presented in Table 4. Interaction energies are calculated for the $\mathrm{FCH}_{2} \mathrm{CO}_{2} \mathrm{H}$ dimers by taking the energy difference between the fragments and the complex. Among the two hydrogen bonded dimers, the more stable one was found to be EC dimer with interaction energies 13.92, 16.92 and 13.51 $\mathrm{kcal} / \mathrm{mol}$ using HF, DFT and MP2 methods, respectively. The relative stability of $\mathbf{E C}$ dimer over $\mathbf{B C}$ dimer was found to be $0.46,0.39$ and $0.49 \mathrm{kcal} / \mathrm{mol}$ by HF, DFT and MP2 methods, respectively. The optimized conformations of $\mathbf{E C}$ and $\mathbf{B C}$ dimers represented in Figure 4.

The substituent effect can be analyzed by comparing the binding energies of acetic acid and fluoroacetic acid. The previously reported binding energy of cyclic and symmetrical dimer of acetic acid calculated at B3LYP/6-311G(d,p) level was found as $15.85 \mathrm{kcal} / \mathrm{mol} .{ }^{19}$ Our calculations show that with replacing of one hydrogen with an electronegative substituent ( $\mathrm{F}$ atom), hydrogen bonding strength decreases. This finding is in accordance with our previously reported finding in substituent effect on hydrogen boning strength of cyclic tetrazole dimers. ${ }^{35}$

Vibrational analysis. The carboxylic acids usually exist as centrosymmetric dimers in crystals with the center of inversion within the eight-membered ring formed by two carboxyl group 
(Figure 3). Vibrational analysis is a useful tool to study the $\mathrm{H}$-bonded clusters. The prediction of the vibrational behavior of $\mathrm{FCH}_{2} \mathrm{CO}_{2} \mathrm{H}$ monomers and dimers was based on B3LYP/ 6-311++G(d,p) results, performed on each stabilized geometry.

The frequencies obtained were then scaled by using a scaling factor, ${ }^{30,33} 0.9614$, which should give good agreement between experimental and theoretical results. Table 5 contains the calculated vibrational frequencies of most favorable conformers of $\mathrm{FCH}_{2} \mathrm{CO}_{2} \mathrm{H}$ monomers with their assignments. The highest frequency $v(\mathrm{OH})$ was observed for conformer ET. The symmetrical C-H stretch was found to be 2934.6, 2906.5, 2939.5 and $2961.5 \mathrm{~cm}^{-1}$ for EC, ET, BC and BT isomers, respectively. The calculated $\mathrm{C}=\mathrm{O}$ stretching for $\mathbf{E C}$-BT monomers was found as $1782.4,1809.9,1744.7$ and $1785.0 \mathrm{~cm}^{-1}$, respectively.

Changes were observed in the calculated vibrational spectrum of fluoroacetic acid from monomers to dimers and they may confirm the results which were obtained on the basis of the calculated geometries and hydrogen-bonding energies. The resulting difference between vibrational frequencies of dimers and monomers calculated at B3LYP/6-311++G(d,p) are collected in the Table 6 . As you can see, all the vibrational modes in hydrogen bonding region show a shift to low wavelength as compared to the individual molecule, a feature that may be attributed to the weakening of the individual bonds along with the charge separation on dimer formation. As can be noticed in

Table 6. Selected calculated stretching vibrational frequencies $\left(\mathrm{cm}^{-1}\right)$ and changes $(\Delta v)$ in the IR frequencies from monomers to dimers of fluoroacetic acid

\begin{tabular}{crrrrr}
\hline & \multicolumn{2}{c}{ EC } & & \multicolumn{2}{c}{ BC } \\
\cline { 2 - 3 } \cline { 5 - 6 } & \multicolumn{1}{c}{$v$} & \multicolumn{1}{c}{$\Delta v$} & & \multicolumn{1}{c}{$v$} & \multicolumn{1}{c}{$\Delta v$} \\
\hline$v_{\mathrm{s}}(\mathrm{OH})$ & 3018.8 & -621.8 & & 2991.7 & -637.9 \\
$\mathrm{v}_{\mathrm{s}}(\mathrm{C}=\mathrm{O})$ & 1678.3 & -108.3 & & 1640.7 & -108.2 \\
$\mathrm{v}_{\mathrm{s}}(\mathrm{O}-\mathrm{C})$ & 1218.9 & 118.4 & & 1274.4 & 137.1 \\
$\mathrm{v}_{\mathrm{s}}(\mathrm{C}-\mathrm{F})$ & 1064.9 & 12.3 & & 1051.0 & 8.9 \\
$\mathrm{v}_{\mathrm{s}}(\mathrm{C}-\mathrm{C})$ & 863.8 & 35.4 & & 859.2 & 38.0 \\
$\mathrm{v}_{\mathrm{ss}}\left(\mathrm{CH}_{2}\right)$ & 2933.9 & -0.7 & & 2936.7 & -0.72 \\
\hline
\end{tabular}

Table 5. The experimental wavenumbers obtained from the IR of difluoroacetic acid and corresponding scaled theoretical wavenumbers of the trans and cis conformers of this molecule calculated at B3LYP/6-311++G(d,p)

\begin{tabular}{|c|c|c|c|c|c|c|c|c|c|c|}
\hline EC & $\exp$ & & ET & & BC & $\exp$ & & BT & $\exp$ & \\
\hline 3616.6 & 3566 & $v(\mathrm{OH})$ & 3644.8 & $v(\mathrm{OH})$ & 3605.0 & 3555 & $v(\mathrm{OH})$ & 3595.3 & 3556 & $v(\mathrm{OH})$ \\
\hline 2980.0 & & $v_{\mathrm{as}}\left(\mathrm{CH}_{2}\right)$ & 2950.5 & $\mathrm{v}_{\mathrm{as}}\left(\mathrm{CH}_{2}\right)$ & 2985.0 & & $v_{\text {as }}\left(\mathrm{CH}_{2}\right)$ & 3017.2 & & $v_{\text {as }}\left(\mathrm{CH}_{2}\right)$ \\
\hline 2934.6 & & $v_{s}\left(\mathrm{CH}_{2}\right)$ & 2906.5 & $v_{s}\left(\mathrm{CH}_{2}\right)$ & 2939.5 & & $v_{s}\left(\mathrm{CH}_{2}\right)$ & 2961.5 & & $v_{s}\left(\mathrm{CH}_{2}\right)$ \\
\hline 1782.4 & 1811 & $v(\mathrm{C}=\mathrm{O})$ & 1809.9 & $v(\mathrm{C}=\mathrm{O})$ & 1744.7 & 1779 & $v(\mathrm{C}=\mathrm{O})$ & 1785.0 & 1804 & $v(\mathrm{C}=\mathrm{O})$ \\
\hline 1415.8 & 1443 & $\mathrm{CH}_{2} \mathrm{scis}$ & 1420.9 & $\mathrm{CH}_{2} \mathrm{scis}$ & 1413.5 & & $\mathrm{CH}_{2} \mathrm{scis}$ & 1411.7 & & $\mathrm{CH}_{2} \mathrm{scis}$ \\
\hline 1366.3 & 1412 & $\mathrm{CH}_{2}$ wag, v(O-C) & 1352.6 & $\begin{array}{l}\mathrm{CH}_{2} \text { wag, } \\
\delta(\mathrm{OHC}), \mathrm{v}(\mathrm{O}-\mathrm{C})\end{array}$ & 1348.1 & 1397 & $\begin{array}{l}\mathrm{CH}_{2} \text { wag, } \\
\text { v(C-C), v(O-C) }\end{array}$ & 1320.7 & 1369 & $\begin{array}{l}\mathrm{CH}_{2} \text { wag, } \\
\delta(\mathrm{OHC}), \mathrm{v}(\mathrm{O}-\mathrm{C})\end{array}$ \\
\hline 1258.9 & 1304 & $\begin{array}{l}\delta(\mathrm{OHC}) \\
v(\mathrm{O}-\mathrm{C}, \mathrm{C}=\mathrm{O})\end{array}$ & 1223.2 & $\delta(\mathrm{OHC}), \mathrm{v}(\mathrm{O}-\mathrm{C})$ & 1320.3 & 1357 & $v(\mathrm{O}-\mathrm{C})$ & 1299.2 & 1328 & $\delta(\mathrm{OHC}), \mathrm{v}(\mathrm{O}-\mathrm{C})$ \\
\hline 1211.1 & & $\rho \mathrm{CH}_{2}$ & 1219.1 & $\rho \mathrm{CH}_{2}, \mathrm{CH}_{2}$ tw & 1217.4 & & $\rho \mathrm{CH}_{2}$ & 1195.4 & & $\rho \mathrm{CH}_{2}, \mathrm{CH}_{2}$ tw \\
\hline 1105.0 & 1119 & $\begin{array}{l}v(\mathrm{C}-\mathrm{F}), \delta(\mathrm{OHC}) \\
\mathrm{v}(\mathrm{O}-\mathrm{C})\end{array}$ & 1087.8 & $\begin{array}{l}\delta(\mathrm{OHC}), \mathrm{v}(\mathrm{O}-\mathrm{C}) \\
\mathrm{v}(\mathrm{C}-\mathrm{F})\end{array}$ & 1142.5 & 1163 & $\delta(\mathrm{OHC}), \mathrm{v}(\mathrm{O}-\mathrm{C})$ & 1154.6 & & $\begin{array}{l}\delta(\mathrm{OHC}), v(\mathrm{O}-\mathrm{C}), \\
v(\mathrm{C}-\mathrm{C})\end{array}$ \\
\hline 1053.0 & 1086 & $\begin{array}{l}v(\mathrm{C}-\mathrm{F}), \mathrm{v}(\mathrm{O}-\mathrm{C}) \\
\delta(\mathrm{OHC})\end{array}$ & 1057.0 & $\begin{array}{l}\mathrm{CH}_{2} \text { wag, v(O-C), } \\
\text { v(C-F), } \delta(\mathrm{OHC})\end{array}$ & 1042.3 & 1082 & $v(C-F)$ & 986.7 & 1035 & $\begin{array}{l}\mathrm{CH}_{2} \mathrm{tw}, \mathrm{C}=\mathrm{O} \text {, } \\
\text { oop wag }\end{array}$ \\
\hline 992.0 & & $\begin{array}{l}\mathrm{CH}_{2} \text { tw, } \mathrm{C}=\mathrm{O} \text {, } \\
\text { oop wag }\end{array}$ & 984.6 & $\begin{array}{l}\mathrm{CH}_{2} \text { tw, } \mathrm{C}=\mathrm{O} \text {, } \\
\text { oop wag }\end{array}$ & 989.6 & & $\begin{array}{l}\mathrm{CH}_{2} \text { tw, } \mathrm{C}=\mathrm{O} \text {, } \\
\text { oop wag }\end{array}$ & 982.3 & & $v(C-F)$ \\
\hline 829.8 & 862 & $v(\mathrm{O}-\mathrm{C}), \mathrm{CCF}$ scis & 830.8 & $v(C-C), v(C-O)$ & 822.7 & 857 & $v(C-C), v(C-O)$ & 830.5 & 860 & $v(\mathrm{C}-\mathrm{C}), \mathrm{v}(\mathrm{O}-\mathrm{C})$ \\
\hline 613.4 & 613 & $\begin{array}{l}\tau(\mathrm{OH}),(\mathrm{C}=\mathrm{O}) \\
\text { oop wag }\end{array}$ & 627.2 & $\begin{array}{l}\text { OCO def, CCF } \\
\text { scis, } \rho \mathrm{C}=\mathrm{O}\end{array}$ & 653.8 & 649 & $\begin{array}{l}\tau(\mathrm{OH}),(\mathrm{C}=\mathrm{O}) \\
\text { oop wag }\end{array}$ & 601.1 & & $\tau(\mathrm{OH})$ \\
\hline 609.1 & & $\begin{array}{l}\mathrm{C}=\mathrm{O}, \mathrm{CCF} \mathrm{s} c i s, \\
\mathrm{v}(\mathrm{O}-\mathrm{C})\end{array}$ & 541.6 & $\tau(\mathrm{OH})$ & 579.2 & 599 & $\begin{array}{l}\text { OCO def, } \\
\text { CCF scis, } \rho \mathrm{C}=\mathrm{O}\end{array}$ & 598.2 & & $\begin{array}{l}\text { OCO def, } \\
\text { CCF scis, } \rho \mathrm{C}=\mathrm{O}\end{array}$ \\
\hline 474.5 & 492 & $\begin{array}{l}\mathrm{C}=\mathrm{O} \text { oop wag, } \\
\mathrm{CH}_{2} \mathrm{tw}, \tau(\mathrm{OH})\end{array}$ & 439.8 & $\begin{array}{l}\text { OCO def, } \\
\text { CCF scis }\end{array}$ & 492.7 & 507 & $\begin{array}{l}\mathrm{C}=\mathrm{O} \text { oop wag, } \\
\mathrm{CH}_{2} \text { tw, } \tau(\mathrm{OH}), \\
\rho \mathrm{CH}_{2}\end{array}$ & 519.6 & 534 & $\begin{array}{l}\mathrm{C}=\mathrm{O} \text { oop wag, } \\
\mathrm{CH}_{2} \text { tw, } \rho \mathrm{CH}_{2}\end{array}$ \\
\hline 441.2 & & $\begin{array}{l}\text { OCO def, } \\
\text { CCF scis, v(C-C) }\end{array}$ & 354.4 & $\begin{array}{l}\mathrm{C}=\mathrm{O} \text { oop wag, } \\
\mathrm{CH}_{2} \text { tw, } \rho \mathrm{CH}_{2}\end{array}$ & 472.1 & & $\begin{array}{l}\rho \mathrm{C}=\mathrm{O}, v(\mathrm{C}-\mathrm{C}) \\
\mathrm{CCF} \text { scis, } \\
\text { OCO def }\end{array}$ & 473.7 & & $\begin{array}{l}\rho \mathrm{C}=\mathrm{O}, v(\mathrm{C}-\mathrm{C}), \\
\mathrm{CCF} \text { scis, } \\
\text { OCO def }\end{array}$ \\
\hline 247.0 & & CCF scis, OCO def & 248.5 & $\begin{array}{l}\text { CCF scis, } \\
\text { OCO def }\end{array}$ & 245.9 & & $\begin{array}{l}\text { CCF scis, } \\
\text { OCO def }\end{array}$ & 272.4 & & $\begin{array}{l}\text { CCF scis, } \\
\text { OCO def }\end{array}$ \\
\hline 78.9 & & $\begin{array}{l}\tau(\mathrm{C}-\mathrm{C}), \mathrm{CH}_{2} \text { tw, } \\
\rho \mathrm{CH}_{2}\end{array}$ & 65.0 & $\begin{array}{l}\tau(\mathrm{C}-\mathrm{C}), \mathrm{CH}_{2} \text { tw, } \rho \\
\mathrm{CH}_{2}\end{array}$ & 52.6 & & $\begin{array}{l}\tau(\mathrm{C}-\mathrm{C}), \mathrm{CH}_{2} \text { tw } \\
\rho \mathrm{CH}_{2}\end{array}$ & 99.4 & & $\begin{array}{l}\tau(\mathrm{C}-\mathrm{C}), \mathrm{CH}_{2} \text { tw } \\
\rho \mathrm{CH}_{2}\end{array}$ \\
\hline
\end{tabular}

wag: wagging, tw: twisting, $\rho$ : rocking, $\tau$ : torsion, $v$ : bond stretching, $\delta$ : in plain angle bending, scis: scissoring. 
our analysis, the calculated vibrational spectra of dimers EC and $\mathbf{B C}$ give evidence of the formation of strong hydrogen bonds involving two $\mathrm{O}-\mathrm{H} \cdots \mathrm{O}=\mathrm{C}$. For the two dimers, elongation of $\mathrm{O}-\mathrm{H}$ bonds results in downshift of the stretching vibrational frequencies. A close look at the Table 6 shows that $\mathbf{B C}$ dimer exhibits a greater shift than $\mathbf{E C}$ dimer. The $\mathrm{C}=\mathrm{O}$ stretching is red shifted by -108.3 and $-108.2 \mathrm{~cm}^{-1}$ for $\mathbf{E C}$ and $\mathbf{B C}$ dimer, respectively. The $\mathrm{C}-\mathrm{O}$ stretching frequency is blue shifted by 118.4 and $137.1 \mathrm{~cm}^{-1}$ for $\mathbf{E C}$ and $\mathbf{B C}$ dimers, respectively. The $\mathrm{C}-\mathrm{H}$ stretching frequency shows a slight change on hydrogen bonding (see Table 6).

NBO analysis. To estimate more precisely the nature of proper hydrogen bonds, we have performed detailed NBO analysis. The nature of the intermolecular hydrogen bonds was analyzed within the framework of the NBO procedure. Table 7 compiles donor-acceptor interactions and their second order perturbation energies $\mathrm{E}^{(2)}$.

Estimates of the second-order perturbative charge-transfer energies listed in Table 7 reveal large contributions arising from the interaction of the lone pairs of the carbonyl oxygen and $\mathrm{O}-\mathrm{H}$ antibonding $\left(\sigma^{*}\right)$ orbitals. The interactions between the second lone pair and the $\mathrm{O}-\mathrm{H}\left(\sigma^{*}\right)$ orbital are larger than the one between the first lone pair and the $\mathrm{O}-\mathrm{H}\left(\sigma^{*}\right)$. Based on results collected in Table 7, it is clear that dimer $\mathbf{B C}$ has stronger hydrogen bond than EC.

Since the hydrogen-bond properties are sometimes evaluated by charge distributions, we considered the atomic charges for

Table 7. Second-order perturbation analysis of the interaction between electron donor and acceptor orbitals in NBO Basis of complexes BC and $\mathbf{E C}$ calculated at different levels.

\begin{tabular}{|c|c|c|c|c|c|c|}
\hline & \multicolumn{2}{|c|}{$\mathrm{HF}$} & \multicolumn{2}{|c|}{ B3LYP } & \multicolumn{2}{|c|}{ MP2 } \\
\hline & EC & BC & EC & BC & EC & BC \\
\hline $\mathrm{LP}(1) \mathrm{O} 1 \rightarrow \sigma^{*} \mathrm{O} 3 \mathrm{H} 4$ & 6.67 & 6.99 & 8.92 & 8.98 & 9.97 & 10.36 \\
\hline $\mathrm{LP}(2) \mathrm{O} 2 \rightarrow \sigma^{*} \mathrm{O} 3 \mathrm{H} 4$ & 8.02 & 8.77 & 19.09 & 19.82 & 19.37 & 20.14 \\
\hline $\mathrm{LP}(1) \mathrm{O} 3 \rightarrow \pi * \mathrm{C} 1 \mathrm{O} 2$ & 10.88 & 11.37 & 9.21 & 0.54 & 10.77 & 11.12 \\
\hline $\mathrm{LP}(2) \mathrm{O} 3 \rightarrow \pi^{*} \mathrm{C} 1 \mathrm{O} 2$ & 75.48 & 84.54 & 57.92 & 63.23 & 75.63 & 85.01 \\
\hline
\end{tabular}

The atom labels are defined in Figure 3. Because of symmetry, results are shown only for one of the monomer units in the dimer. the included atoms for better understanding of the problem. The calculated values NBO charges using the Natural Population Analysis (NPA) at optimized structures of fluoroacetic acid monomers in the gas phase are given in Table 8 . The calculated charge distributions for dimers resulting from hydrogen bonding are presented in Table 9. It can be observed that, due to complexation, hydrogen atoms involved in hydrogen bonding gain more positive charges, the oxygen atoms acting as hydrogen acceptor gain more negative charges, and the charges on the oxygen atoms acting as hydrogen donor diminish as compared with monomers. However, the charges on atoms that don't participate in hydrogen bonding slightly changed (see Table 9).

AIM electron density at bond critical points. The "atoms in molecules" theory of Bader (AIM) ${ }^{36}$ is a very useful method for the estimation of hydrogen bond energy. ${ }^{37-39}$ The Bader theory is based on topological properties of the electron density $\left(\rho_{b}\right)$, and Laplacian of the electron density $\left(\nabla^{2} \rho_{b}\right)$ at the bond critical points (BCP) of two hydrogen bonded atoms. The atomic interactions were classified in two general classes, shared interactions and closed-shell interactions. The shared interactions (as in covalent and polar bonds) are caused by a contraction of the charge density towards the line of interaction linking the nuclei. For these interactions the electronic charge is concentrated in the internuclear region with $\nabla^{2} \rho_{b}<0$. The closed-shell interactions (as in Hydrogen bonds and van der Waal's interactions) are governed by the contraction of the charge density toward each of the interacting nuclei. In this case, the elect-

Table 9. NBO charges for $\mathbf{E C}$ and $\mathbf{B C}$ dimers calculated at the B3LYP/6-311++G(d,p) level

\begin{tabular}{rrrrrrrrr}
\hline & \multicolumn{3}{c}{ HF } & & \multicolumn{2}{c}{ B3LYP } & & \multicolumn{2}{c}{ MP2 } \\
\cline { 1 - 3 } \cline { 7 - 8 } \cline { 7 - 8 } O1 & \multicolumn{1}{c}{ EC } & \multicolumn{1}{c}{ BC } & & \multicolumn{1}{c}{ EC } & \multicolumn{1}{c}{ BC } & & EC & \multicolumn{1}{c}{ BC } \\
C2 & 0.935 & -0.762 & & -0.639 & -0.670 & & -0.741 & -0.776 \\
O3 & -0.756 & -0.728 & & -0.685 & -0.654 & & -0.767 & -0.737 \\
H4 & 0.537 & 0.535 & & 0.515 & 0.513 & & 0.542 & 0.540 \\
C5 & 0.085 & 0.085 & & 0.002 & 0.003 & & 0.079 & 0.080 \\
F6 & -0.400 & -0.401 & & -0.368 & -0.371 & & -0.404 & -0.406 \\
H7 & 0.164 & 0.165 & & 0.192 & 0.193 & & 0.171 & 0.172 \\
H8 & -0.727 & -0.762 & & -0.639 & -0.670 & & -0.741 & -0.776 \\
\hline
\end{tabular}

Table 8. NBO charges for EC-BT monomers calculated at the B3LYP/6-311++G(d,p) level

\begin{tabular}{|c|c|c|c|c|c|c|c|c|c|}
\hline & & $\mathrm{O}_{1}$ & $\mathrm{C}_{2}$ & $\mathrm{O}_{3}$ & $\mathrm{H}_{4}$ & $\mathrm{C}_{5}$ & $\mathrm{~F}_{6}$ & $\mathrm{H}_{7}$ & $\mathrm{H}_{8}$ \\
\hline \multirow{3}{*}{ EC } & $\mathrm{HF}$ & -0.650 & 0.900 & -0.751 & 0.493 & 0.084 & -0.400 & 0.161 & 0.161 \\
\hline & B3LYP & -0.561 & 0.758 & -0.695 & 0.489 & -0.003 & -0.368 & 0.190 & 0.190 \\
\hline & MP2 & -0.656 & 0.907 & -0.758 & 0.496 & 0.078 & -0.404 & 0.168 & 0.168 \\
\hline \multirow{3}{*}{ ET } & $\mathrm{HF}$ & -0.613 & 0.889 & -0.728 & 0.470 & 0.072 & -0.393 & 0.151 & 0.151 \\
\hline & B3LYP & -0.525 & 0.751 & -0.674 & 0.468 & -0.020 & -0.362 & 0.181 & 0.181 \\
\hline & MP2 & -0.618 & 0.894 & -0.732 & 0.469 & 0.067 & -0.398 & 0.159 & 0.159 \\
\hline \multirow{3}{*}{ BC } & $\mathrm{HF}$ & -0.686 & 0.907 & -0.721 & 0.491 & 0.083 & -0.404 & 0.165 & 0.165 \\
\hline & B3LYP & -0.594 & 0.760 & -0.662 & 0.487 & 0.003 & -0.373 & 0.193 & 0.193 \\
\hline & MP2 & -0.693 & 0.915 & -0.727 & 0.493 & 0.076 & -0.408 & 0.172 & 0.172 \\
\hline \multirow{3}{*}{ BT } & $\mathrm{HF}$ & -0.651 & 0.897 & -0.721 & 0.494 & 0.066 & -0.429 & 0.172 & 0.172 \\
\hline & B3LYP & -0.558 & 0.752 & -0.662 & 0.490 & 0.023 & -0.397 & 0.199 & 0.199 \\
\hline & MP2 & -0.658 & 0.903 & -0.726 & 0.496 & 0.061 & -0.435 & 0.180 & 0.180 \\
\hline
\end{tabular}


Table 10. Analysis of $\mathrm{O} 1-\mathrm{H} 4$ and $\mathrm{H} 4 \cdots \mathrm{O} 1$ ' bond critical points in the fluoroacetic acid All quantities are in atomic unit

\begin{tabular}{crrrrr}
\hline \multirow{2}{*}{ Bond } & \multicolumn{2}{c}{ EC } & & \multicolumn{2}{c}{ BC } \\
\cline { 2 - 3 } \cline { 5 - 6 } & $\nabla^{2} \rho_{\mathrm{b}}$ & $\rho_{\mathrm{b}}$ & & $\nabla^{2} \rho_{\mathrm{b}}$ & $\rho_{\mathrm{b}}$ \\
\hline O1-H4 & -0.223 & 0.320 & & -0.222 & 0.330 \\
H4 $\cdots$ O1' & 0.135 & 0.046 & & 0.136 & 0.047
\end{tabular}

$\rho_{b}$ is the value of the electron density at the bond critical point, $\nabla^{2} \rho_{b}$ is the second derivative of the electron density.

ronic charge is depleted in the interatomic surface with $\nabla^{2} \rho_{\mathrm{b}}>0$. To obtain additional information about the strengths of the $\mathrm{O} \cdots \mathrm{H}$ hydrogen bonding in $\mathbf{E C}$ and $\mathbf{B C}$ dimmers, we undertook AIM study of the electron density at bond critical points. Table 10 contains the electron density at $\mathrm{H}$-bond critical points as well as at the $\mathrm{H}-\mathrm{O}$ bonds in two dimers calculated at B3LYP/ $6-311++G(d, p)$ level of theory. The HBs in EC and BC are symmetrical and the calculated $\rho_{b}$ and $\nabla^{2} \rho_{b}$ for both $\mathrm{O} \cdots \mathrm{H}$ bondings are obtained as identical. The $\mathrm{O} \cdots \mathrm{H}$ hydrogen bonds in above-mentioned dimers exhibit properties of low $\rho_{b}$ and positive $\nabla^{2} \rho_{b}$ typical of closed-shell interactions, whereas the $\mathrm{H}-\mathrm{O}$ bonds have features typical for covalent interactions.

As shown in Table 10, the values of $\rho_{b}$ for $\mathrm{H} 4 \cdots \mathrm{O} 1$ ' in the complex EC and BC are 0.017 and 0.020 a.u., and those of $\nabla^{2} \rho_{b}$ are 0.135 and 0.136 a.u., respectively. All $\nabla^{2} \rho_{b}$ at BCPs are positive, which indicate they are closed-shell interactions. In addition, the electron density of bond critical points fall 0.002 0.04 a.u., satisfying the criteria proposed by Popelier for hydrogen bond formation. ${ }^{40}$

Proton transfer processes in the dimers. The proton transfer reaction is a very important biochemical process, which may occur directly without any assistance of the solvent molecule or assisted by one or more solvent molecule. In Figure 5 the optimized structures of the transition states in proton transfer reactions of EC and BC dimers obtained by B3LYP method are presented.

The activation energies for hydrogen transfer reaction between fluoro acetic acid dimer were found to be 6.51 and 8.14 $\mathrm{kcal} / \mathrm{mol}$ for $\mathbf{E C}$ and $\mathbf{B C}$ dimers, respectively. These values are slightly lower than activation energy that was calculated for acetic acid dimmer at same level of theory $(8.57 \mathrm{kcal} / \mathrm{mol})$. One can conclude that the lower barrier obtained for proton transfer reaction in fluoroacetic acid dimer than in acetic acid dimer is due to larger acidity of fluoroacetic acid, resulting from the strong inductive (electron-withdrawing) effects of -F vs.-H. It seems that the proton transfer in fluoroacetic acid dimer involves simultaneous movements of two protons (double proton transfer).

\section{Conclusion}

The hydrogen bond interaction of 1:1 complex between fluoroacetic acid and flouracetic acid has been analyzed by ab initio, MP2 and B3LYP methods employing the 6-311++G(d,p) basis set. Four monomers and two dimers were considered and frequency analysis suggests that these structures are local

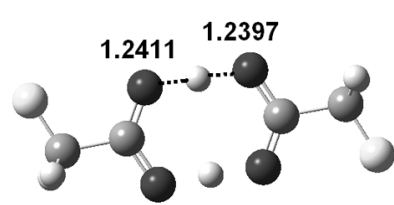

EC

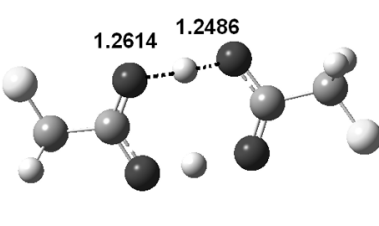

$\mathrm{BC}$
Figure 5. The optimized structures of transition states of hydrogen transfer in the EC and BC dimers calculated at B3LYP/6-311++G(d,p) level of theory.

minima. All methods predict that the order of stability is $\mathbf{E C}>$ BC $>$ BT $>$ ET. The interaction energy of fluoroacetic acid dimers indicates that they enough to overcome the relative stability of the monomers and dimer formation. In addition, comparison of $\mathbf{E C}$ and $\mathbf{B C}$ dimers shows that $\mathbf{E C}$ is slightly more stable.

Complexation in $\mathrm{FCH}_{2} \mathrm{CO}_{2} \mathrm{H}$ causes changes in the geometrical parameters in monomer so that carbonyl and carboxylic acid hydrogen bond lengths increase. The dimerization of fluoroacetic acid leads to significant changes in the vibrational characteristics of the monomer unit. The large shifts of the most sensitive aggregation vibrations $(\mathrm{O}-\mathrm{H}$ and $\mathrm{C}=\mathrm{O}$ stretchings $)$ confirmed the cooperative effect in the cyclic structures. NBO analysis has been performed to calculate charges on atoms and to explore the nature of the bonds of the clusters. In comparison with acetic acid, it was found that replacement of hydrogen by an electron withdrawing group leads to a decrease of strength of hydrogen bonding. The AIM analysis of charge density showed that the two studied dimers satisfy the criteria of hydrogen bonding interaction. The proton transfer reaction in the dimmers was studied and activation energies were calculated.

Acknowledgments. This work was carried out with financial support of Yasouj University (YU). Authors would like to thank Dr. Shapour Ramazani for his technical assistance in calculation of transition states.

\section{References}

1. Scheiner, S. Hydrogen Bonding; Oxford University Press: New York, 1997.

2. Jeffery, G. A. In Introduction to Hydrogen Bonding; Oxford University Press: New York, 1997.

3. Hobza, P.; Havlas, Z. Chem. Rev. 2000, 100, 4253.

4. Genin, F.; Quiles, F.; Burneau, A. Phys. Chem. Chem. Phys. 2001, 3,932 .

5. Emmeluth, C.; Suhm, M. A. Phys. Chem. Chem. Phys. 2003, 5, 3094.

6. Goldman, M. A.; Emerson, M. T. J. Phys. Chem. 1973, 77, 2295.

7. Lumbroso-Bader, N.; Coupry, C.; Baron, D.; Clague, D. H.; Govil, G. J. Magn. Res. 1969, 17, 386 .

8. Yoshida, N. J. Phys. Chem. 1982, 86, 1785.

9. Stricter, F. J.; Templeton, D. H.; Scheuerman, R. F.; Sass, R. L. Acta Crysrallogr. 1962, 15, 1233.

10. Kanters, J. A.; Kroon, J. Acta Crysrallogr. 1972, 828, 1946.

11. Albinati, A.; Rouse, K. D.; Thomas, M. W. Acta Crystallogr., B: Struct. Crystallogr. Crystal Chem. 1978, 34, 2188.

12. (a) Van Eijck, B. P.; Brandts, P.; Maas, J. P. M. J. Mol. Struct. 1978, 44, 1. (b) Van Eijck, B. P.; Van Der Plaats, G.; Van Rogn, P. H. J. Mol. Struct. 1972, 11, 67.

13. Taylor, M. D. J. Am. Chem. Soc. 1951, 73, 315.

14. Frurip, D. J.; Curtiss, L. A.; Blander, M. J. J. Am. Chem. Soc. 1980, 
$102,2610$.

15. Aquino, A. J. A.;Tunega, D.; Haberhauer, G.; Gerzabek, M. H.; Lischka, H. J. Phys. Chem. 2002, 106, 1862.

16. Turi, L. J. Phys. Chem. 1996, 100, 11285.

17. Wolfs, I.; Desseyn, H. O. J. Mol. Struct. (Theochem) 1996, 81, 360.

18. Lewandowski, H.; Koglin, E.; Meier, R. J. Vibrational Spectroscopy 2005, 39, 15.

19. Chocholousova, J.; Vacek, J.; Hobza, P. J. Phys. Chem. 2003, 107, 3086.

20. Turi, L.; Dannenberg, J. J. J. Phys. Chem. 1993, 97, 12197.

21. Holtzberg, F.; Post, B.; Fankuchen, I. Acta Crystallogr. 1953, 6, 127.

22. Nahringbauer, I.; Acta Crystallogr. Sect. B: Struct. Crystallogr. Cryst. Chem. 1978, 34, 315.

23. Allan, D.; Clark, S. J. Phys. Rev. Lett. 1999, 82, 3464.

24. (a) Gavezzotti, A. Chem. Eur. J. 1999, 5, 567. (b) Gao, J.; Pavelites, J. J. J. Am. Chem. Soc. 1992, 114, 1912.

25. Gavezzotti, A.; Filippini, G.; Kroon, J.; van Eijck, B. P.; Klewinghaus, P. Chem. Eur. J. 1997, 3, 893.

26. Blom, C. E.; Gunthard, H. H. Chem. Phys. Lett. 1981, 84, 267.

27. Nieminen, J.; Pettersson, M.; Rasanen, M. J. Phys. Chem. 1993, 97, 10925 .

28. Frisch, M. J. et al., Gaussian 03, Revision C.02, Gaussian Inc.,
Pittsburg, PA, 2003.

29. Frisch, A.; Nielsen, A. B.; Holder, J. Gauss View User Manual, Gaussian.

30. Young, C. Computational Chemistry, A Practical Guide for Applying Techniques to Real-World Problems (Electronics); John Wiley and Sons, Inc.: New York, 2001.

31. (a) Boys, S. F.; Bernardi, F. Mol. Phys. 1970, 19, 553. (b) Boys, S. F.; Bernardi, F. Reprinted in Mol. Phys. 2002, 100, 65.

32. Glendening, E. D.; Badenhoop, J. K.; Reed, A. E.; Carpenter, J. E.; Weinhold, NBO Version 3.1, Theoretical Chemistry Institute, University of Wisconsin, Madison.

33. Borisenko, K. B.; Bock, C. W.; Hargittai, I. J. Mol. Struct. (Theochem) 1995, 332, 161.

34. Anderson, P.; Uvdal, P. J. Phys. Chem. A 2005, 109, 2937.

35. Chermahini, A. N.; Ghaedi, A.; Teimouri, A.; Momenbeik, F.; Dabbagh, H. A. J. Mol. Struct. (Theochem) 2008, 78, 867.

36. Bader, R. F. W. Atoms In Molecules. A Quantum theory; Oxford University Press: New York, 1990.

37. Carrol, M. T.; Chang, C.; Bader, R. F. W. Mol. Phys. 1988, 63, 387.

38. Carrol, M. T.; Chang, C.; Bader, R. F. W. Mol. Phys. 1998, 65, 695.

39. Koch, U.; Popelier, P. J. Chem. Phys. 1995, 99, 9747.

40. Popelier, P. L. A. Atoms in Molecules: An Introduction; Pearson Education Limited: Edinburgh Gate, Harlow, England, 2000. 